\title{
Correction to: Deformation characteristics, mechanisms, and influencing factors of hydrodynamic pressure landslides in the Three Gorges Reservoir: a case study and model test study
}

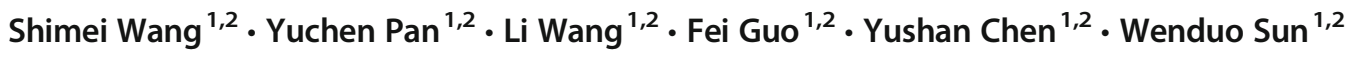 \\ Published online: 22 February 2021 \\ (C) Springer-Verlag GmbH Germany, part of Springer Nature 2021
}

Correction to: Bulletin of Engineering Geology and the Environment (2021)

https://doi.org/10.1007/s10064-021-02120-w

The original article contains three errors. 1) In the fourth column of Table 2, the unit of the "Permeability coefficient" should be " $\mathrm{cm} / \mathrm{s}$ " instead of " $\mathrm{m} / \mathrm{s}$ ". 2) In the second paragraph of Introduction, the citation "Cho and Lee (2011)" should be changed to "Egeli and Pulat (2011)". 3) In the references, "Cho SE, Lee SR (2011)" should be changed to "Egeli I, Pulat HF (2011)".

The original article has been corrected.

The online version of the original article can be found at https://oi.org/ 10.1007/s10064-021-02120-w

Li Wang

592786913@qq.com

1 Key Laboratory of Geological Hazards on Three Gorges Reservoir Area, Ministry of Education, China Three Gorges University, Yichang 443002, Hubei, China

2 National Field Observation and Research Station of Landslides in Three Gorges Reservoir Area of Yangtze River, China Three Gorges University, Yichang 443002, Hubei, China 